\title{
EUTOMIA
}

Revista de Literatura e Linguística

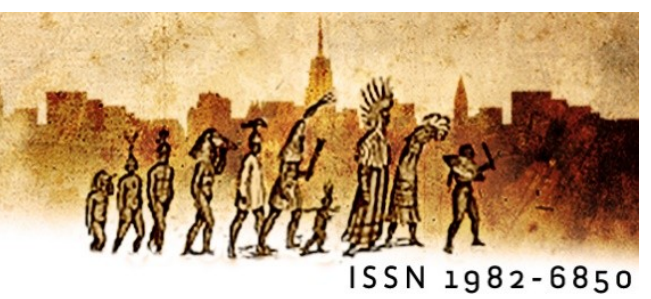

\section{Os adolescentes falando: entrevistas, diários de campo e o papel do pesquisador enquanto ouvinte}

\section{Adolescents speaking: interviews, field diaries, and the researcher's role as listener}

\author{
Kalina Vanderlei Silva' (UPE) \\ Simonelly Ferreira Vilelai" (UPE) \\ Douglas Batista de Oliveiraiii (UPE) \\ Anderson Vicente da Silvaiv (UPE)
}

\begin{abstract}
Resumo: Este artigo busca realizar uma reflexão epistemológica acerca do papel do cientista enquanto ouvinte, assumido durante a aplicação de entrevistas e observações participativas empregadas como instrumentos de coleta de dados em pesquisas interdisciplinares. Para tanto, toma como base a experiência de coleta de dados em um projeto interdisciplinar sobre identidades de adolescentes em Recife, cotejada com reflexões teóricas de disciplinas como a História Oral, a Análise do Discurso e a Etnografia.

Palavras-chave: metodologia; interdisciplinaridade; adolescentes; identidades; oralidade.
\end{abstract}

\begin{abstract}
This paper seeks to carry out an epistemological reflection on the place of the scientist as a listener during interdisciplinary research that used interviews and participant observations as techniques. To this end, the paper analyzes the experience of collecting data for interdisciplinary research on youth identities in the Brazilian city of Recife through the lens of oral history, discourse analysis, and ethnography.

Keywords: methodology; interdisciplinarity; adolescence; identities; orality.
\end{abstract}

\section{Introdução}

Atualmente, epistemologias vigentes em diferentes disciplinas científicas, entre a Psicologia, a Antropologia, a História e a Saúde Coletiva, colocam frequentemente o pesquisador no papel de entrevistador ao definir os indivíduos observados como fontes de 
conhecimento ou informações que merecem registro, enquanto a Etnografia instrumentaliza a observação participativa como um veículo cientificamente viável para a coleta de dados. Em um e outro caso, seja como entrevistador ou como observador que interage diretamente com os sujeitos estudados, o pesquisador social assume um papel, para além do de analista, que merece maiores escrutínios: o papel de ouvinte.

Essa posição está intrinsecamente entrelaçada ao dilema ético entre, de um lado, a vontade de garantir aos atores sociais a propriedade de suas falas, de registrar sua agência e Ihes atribuir historicamente o protagonismo que já exercem em seu meio social, e, por outro lado, a obrigação cientifica de analisar falas, gestos e hábitos em seus significados sociais e enquanto ferramentas de reprodução das representações sociais e da dominação simbólica. Esse dilema passa pelo lugar do pesquisador enquanto ouvinte que, como em todo diálogo, não é um lugar de passividade, já que é através do ouvinte que a própria fala atua sobre o mundo (PEREIRA, 2007). Mesmo o pesquisador que acredita apenas olhar ou apenas escutar, gravando as falas e atos dos sujeitos foco de sua atenção, não está 'apenas' olhando ou escutando, mas, conforme as premissas de Bakhtin, está desempenhando um papel ativo na interação, respondendo com uma compreensão ativa (PIRES, 2003). próprio Bakhtin analisou a relação dialógica entre os gêneros primários e secundários do discurso na qual os diálogos científicos, um gênero secundário, usam os diálogos cotidianos, gênero primário, como fontes sem deixar de influenciar também a estes. Nesse sentido, enquanto o pesquisador se utiliza das entrevistas e observações participativas para registrar os discursos de seus sujeitos, ele está, ao mesmo tempo, exercendo uma influência direta sobre os sujeitos que falam, fazendo com que sua própria presença enquanto ouvinte influencie a fala alheia.

Mas se hoje essa posição é clara em disciplinas como a Antropologia, a Linguística e a História, ainda existe o risco de que a tradução de técnicas como a entrevista por análises interdisciplinares, tais como as pesquisas qualitativas da área de Saúde, seja feita sem a devida consideração dessas inquietações teóricas em torno tanto do lugar do cientista enquanto ouvinte, quanto da própria pesquisa social como um diálogo. Inquietações, por sua vez, que dizem respeito a natureza mesma da identidade cientifica em um momento como o atual onde proliferam fragmentações, incertezas e transversalidades criadas pela pós-modernidade (PRYSTHON, 2002; HALL, 2006). 
Não coincidentemente as identidades estão entre os objetos de estudo que a pósmodernidade fez germinar em disciplinas nas quais o papel de ouvinte do pesquisador é acentuado: como na interconexão entre identidade, memória e oralidade na História Oral (MEIHY, 2002). De fato, as identidades se tornaram um tema caro às disciplinas humanistas do séc. XXI, tendo brotado da Psicanálise novecentista, sido relida pelos Estudos Culturais e se multiplicado em uma miríade de trabalhos interdisciplinares construídos em torno de inquietudes pós-modernas basilares como os nacionalismos, os hibridismos e as mestiçagens, a fragmentação das identidades de gênero e o abismo entre globalização e pobreza (HALL, 2006; ABDALA JUNIOR, 2002).

E é partindo dessas considerações que o presente artigo busca refletir sobre o papel do pesquisador enquanto ouvinte a partir da experiência com a aplicação de instrumentos de coleta de dados nos quais esse lugar de escuta é fundamental. Uma experiência que tomou forma na execução de uma pesquisa interdisciplinar que transita entre as Ciências Humanas e as da Saúde: o projeto "As Representações sobre Identidades e Gênero construídas por Adolescentes da Região Metropolitana do Recife", iniciado em 2017, cuja metodologia se fundamenta sobre ferramentas da História Oral, da Antropologia, da Psicologia Social, da Linguística e da Saúde Coletiva para permitir o desenho de um perfil das identidades adolescentes na cidade do Recife no século XXI. ${ }^{1}$ Um estudo preocupado com os contornos das construções identitárias produzidas por atores sociais imersos em contextos contraditórios da pós-modernidade.

E sobreposições e transversalidades estão no cerne desse trabalho, a começar pelo próprio cenário de estudo, a capital pernambucana. O Recife é uma cidade onde a pósmodernidade se confronta com a herança do 'terceiro mundo', ao mesmo tempo historicamente patriarcal e lar de um crescente movimento LGBT+, e onde a população crescente e desigual de adolescentes produz diferentes nichos culturais para se expressar, elaborando suas identidades e seus papeis de gênero em meio a influência de famílias, igrejas, comunidades, escolas, mas também da mídia, das redes sociais e da internet (PRYSTHON, 2002; FRANCH, 2002). Ao mesmo tempo, as escolas de ensino fundamental e médio, onde esses jovens passam considerável parcela de suas vidas, são alvo de toda uma luta de representações, como o conflito gerado em torno do crescimento do fundamentalismo cristão, exemplificado na tentativa de impor ensino religioso às escolas

\footnotetext{
${ }^{1}$ Dados do projeto.
} 
públicas realizada pela Câmara de Vereadores de Jaboatão, respaldado pela nova Base Nacional Comum Curricular (BNCC), aprovada em dezembro de 2018 (JABOATÃO DOS GUARARAPES, 2016; BRASIL, 2018).

Então, investigar as identidades adolescentes nesse cenário é buscar os processos socioculturais que desenham definições de gêneros, etnias, religiosidades e regionalidades em meio ao caos de uma cidade brasileira do século $X X X I_{i}$ processos que podem ser acessados a partir de um conjunto variado de fontes primárias, mas principalmente a partir dos discursos - sejam midiáticos, sejam governamentais, sejam religiosos - que levam aos sistemas de representações dominantes em diferentes esferas (JODELET, 2001; ORLANDI, 2005). E entre os discursos chave para tal investigação estão aqueles de adolescentes de diferentes grupos sociais e que podem ser acessados de forma privilegiada a partir do registro de suas falas, que colocam os pesquisadores fundamentalmente no lugar de ouvintes.

\section{Entrevistas e Observações}

Provavelmente a ferramenta das Ciências Sociais mais largamente empregada em pesquisas interdisciplinares, a entrevista, com suas origens jornalísticas e policiais, presta-se a uma transposição fácil entre diferentes disciplinas, ao mesmo tempo em que posiciona, como poucas outras técnicas, o pesquisador primeiramente enquanto ouvinte. As contribuições dessa técnica para as Ciências Sociais são inúmeras, dificilmente cabendo no escopo de um único trabalho. $E$, no entanto, o ato de entrevistar ainda merece profundos escrutínios, principalmente a partir de uma perspectiva interdisciplinar. Isso porque se a entrevista registra a fala e a experiência de atores sociais muitas vezes destituídos de voz pública, ela também pode vulnerabilizar o sujeito entrevistado, transformando-o em potencial objeto de experimentos e expondo sua experiência intima ao olhar público.

Tal dualidade ainda alimenta discussões sobre a necessidade de que todos os pesquisadores sociais se submetam a uma revisão ética antes do início da coleta de dados (DINIZ, 2008; REVISÃO ÉTICA NA PESOUISA EM CIÊNCIAS HUMANAS E SOCIAIS, 2015). Essa questão inspirou o Conselho Nacional de Saúde (CNS) a elaborar um código de ética para as pesquisas em Ciências Humanas e Sociais, a Resolução 510/2016 (BRASIL, 2016). A abordagem que levou à elaboração de tal documento parte do princípio de que a entrevista 
não é apenas uma técnica de coletas de dados, mas uma forma de experimentação com seres humanos e por isso passível de abusos. Por outro lado, como afirma Silveira (2007), para as Humanidades, o registro do testemunho oral é o registro das vozes de atores sociais marginalizados, de sua memória e de sua própria identidade, uma premissa que contraria a regra do anonimato imposta pelos comitês de ética. Essa linha de pensamento vem criando, desde o final do século $X X$, repositórios de entrevistas que não apenas registram, mas salvaguardam e disponibilizam os testemunhos de diferentes atores sociais, enfatizando suas histórias de vida, com o intuito principal de preservar a memória de personagens fora dos circuitos centrais da história. Várias instituições têm criado esses repositórios, como, por exemplo, o programa de História Oral do Centro de Pesquisa e Documentação de História Contemporânea do Brasil da Fundação Getúlio Vargas (CPDOC/FGV), que conta com cerca de 900 entrevistas transcritas e disponíveis para download com suas autorias registradas, realizadas através de diferentes projetos. ${ }^{2}$

Assentados na fronteira entre essas posições diametralmente opostas, os pesquisadores envolvidos na pesquisa sobre identidades adolescentes, à medida em que cotejavam as teorias que norteavam seu trabalho com a realidade da coleta de dados, sentiram-se envolvidos pelo dilema gerado por uma metodologia que propunha o cruzamento de técnicas e considerações teóricas da História Oral - inclusive sua ênfase na valorização das experiências históricas dos entrevistados através do tratamento de suas falas como fontes documentais - , e de abordagens e preocupações da Saúde Coletiva, com sua insistência no anonimato dos entrevistados, entendidos como participantes de uma pesquisa quase laboratorial. Um dilema acentuado pela definição da entrevista como ferramenta principal de coleta de dados, visto as possibilidades de acesso que ela confere a discursos, sistemas de valores e conjuntos de representações dos sujeitos falantes. Um acesso tanto mais profundo quanto mais aberta e menos dirigida ela for (BELEl et al., 2008; DUARTE, 2004; BONI, QUARESMA, 2005).

\footnotetext{
${ }^{2}$ Repositório do CPDOC/ FGC: https://cpdoc.fgv.br/acervo/historiaoral/entrevistas; Repositório de Entrevistas de História Oral da Universidade Federal do Rio Grande do Sul (REPHO/UFRGS) https://www.ufrgs.br/repho/o-repho/; Memórias Científicas - Memória e Repositório de entrevistas do Grupo Informação, Memória e Sociedade: http://www.memoriascientificas.ibict.br/category/entrevista/; Acervo de Depoimentos Orais, Casa de Oswaldo Cruz: http://www.coc.fiocruz.br/index.php/pt/patrimonio-cultural/acervo-arquivistico/acervo-de-historia-oral; Acervo de História Oral da Rede de Memória do IBGE: https://memoria.ibge.gov.br/historia-oral.html.
} 
Nesse dilema ético, prevaleceram as exigências do CNS, expressas na Resolução 510/2016, principalmente dado ao fato dos sujeitos participantes do trabalho serem adolescentes. Logo, a transcrição de suas entrevistas foi feita baixo a proteção de pseudônimos. No entanto, isso não apagou o compromisso com a preservação das vivências dos entrevistados, ainda mais acentuada dado à convivência etnográfica dos pesquisadores com os jovens.

De fato, se a principal forma de coleta de dados foi a entrevista aberta, que procurava tomar a forma de uma 'conversa' na qual o papel de ouvinte do pesquisador se mostrou vital, exigindo do mesmo interação e escuta ativa, a imersão dos pesquisadores na realidade dos grupos estudados, através dos métodos etnográficos que configuram a observação participativa, por sua vez, também se mostrou imprescindível para a compreensão dos contextos no qual discursos e representações eram construídos. Isso porque o convívio com o grupo garante ao pesquisador, em comparação a uma investigação que parte do exterior, uma posição mais favorável para a atribuição de significados a acontecimentos e práticas por parte dos integrantes do grupo (MÓNICO et al., 2017). E essa posição de observador também exige um posicionamento de ouvinte que dialoga e escuta ativamente. E se várias são as propostas na literatura acadêmica acerca do que pode ser nomeado como observação participante, na pesquisa sobre identidades adolescentes prevaleceu a posição segundo a qual tal observação inevitavelmente estabelece um grau de envolvimento do pesquisador com seu objeto de estudo (ANGROSINO, 2009). Assim, se os pesquisadores não se tornaram exatamente membros dos grupos estudados (SILVA, 2013), pelo menos buscaram participar ativamente nas atividades das comunidades investigadas, mais uma vez atuando como os ouvintes ativos de uma conversa dialogada.

Tal experiência produziu diários de campo, ferramenta comumente associada à observação participante, que se tornaram não apenas fontes para os conjuntos de representações dos adolescentes, mas para a própria experiência dos pesquisadores ouvindo e dialogando com os sujeitos da pesquisa, e, logo, modificando-se ao mesmo tempo que influíam com os falantes/ouvintes. Os diários, com seu caráter intimista e flexível (OLIVEIRA, 2014), foram tomando a forma de descrições objetivas de cenários, pessoas e situações misturadas com impressões e interpretações dos observadores no campo, e deixando claro o quanto o ato de ouvir e o ato de observar realizado pelos cientistas sociais 
eram muito mais ativos do que muitas abordagens de pesquisa qualitativa consideram possível ou viável cientificamente.

\section{Ouvindo os Adolescentes do Recife}

Visto o enfoque da pesquisa recair sobre atores sociais das periferias do Recife - um recorte que abrange uma grande diversidade social, cultural, religiosa e, logo, identitária tornou-se necessário definir, antes de mais nada, que grupos específicos de jovens seriam observados, o que levou ao envolvimento, na primeira fase do projeto realizada entre 2018 e 2019, de dois grupos diferentes de adolescentes, ambos periféricos, ambos vinculados à rede pública de educação do Estado de Pernambuco, mas distanciados entre si por um elemento específico de suas construções identitárias, a identidade religiosa: por um lado, os jovens atuantes em organizações lúdicas católicas, por outro, adolescentes devotos de terreiros de candomblé.

O primeiro grupo abrange adolescentes católicos do bairro do Pina, na cidade do Recife-PE, cujo diálogo com os pesquisadores começou no final do primeiro semestre de 2018. De início, várias agremiações de adolescentes católicos foram procuradas na vizinhança de Brasília Teimosa, um bairro popular e central, sendo o Grupo Teatral Aquiles Coqueiro (GTAC), atuante na Paróquia do Pina, aquele que apresentou maior abertura para realização da pesquisa. Os componentes do GTAC são adolescentes de ambos os sexos matriculados na Escola de Referência em Ensino Médio João Bezerra, em Brasília Teimosa, vizinho ao bairro do Pina, que se reúnem não apenas por um interesse religioso comum, mas pelo desejo de montar produções artísticas de dança e teatro.

A coleta de dados começou com a inserção dos pesquisadores nas atividades do GTAC, na escola e na igreja, com a observação do desenrolar destas. Seguindo a premissa que considera que a realização de uma entrevista deve começar pela análise do contexto do entrevistado (BRITTO JUNIOR; FERES JUNIOR, 2011), buscamos implementar a observação participativa como método para visualizar e compreensão do contexto social, cultural e histórico dos integrantes da amostra. A partir daí, as entrevistas foram feitas tendo a religiosidade como tema central de uma conversa dirigida por um roteiro mínimo de perguntas elaboradas previamente com base nos estudos preliminares, mas procurando tomar o máximo possível a forma de um diálogo no qual o entrevistado desse a direção da 
conversa. Atentando não apenas para o dito, mas para os silêncios, gestos, risadas, reticências e pausas, e respeitando o espaço e tempo de cada um, os entrevistadores, ao assumirem um papel de ouvintes atentos que não apenas buscavam respostas especificas para perguntas rígidas, mas atentavam para os temas aparentemente secundários trazidos pelos falantes à conversa, terminaram por ajustar o próprio foco temático da pesquisa, visto que ao começar a conversar sobre religiosidade foram levados pelos jovens entrevistados a perceber que os mesmos construíam uma interrelação entre esse tema e o desempenhar de atividades artísticas. Nesse sentido, a coleta de dados realizada a partir de posturas teóricas que consideravam a natureza dialógica da entrevista permitiu que todo um novo conjunto de resultados fosse trazido à tona. Em parte, isso foi possível graças à possibilidade de articular os aspectos socioculturais observados e vivenciados pelos pesquisadores com as possibilidades de coleta por meio da entrevista.

Por sua vez, o segundo grupo trabalhado é composto por adolescentes praticantes do candomblé que foram abordados a partir das mesmas premissas metodológicas. No que diz respeito à inserção dos pesquisadores no campo, eles se colocaram no lugar de observadores participantes de atividades, inclusive cerimônias religiosas, em dois centros de candomblé situados no município de Olinda, na Região Metropolitana do Recife - PE. Essa inserção possibilitou uma aproximação à dinâmica dos grupos que foi traduzida em descrições postas em um diário de campo, ferramenta fundamental para a análise. Isso porque esses diários são o produto da incorporação orgânica do pesquisador junto ao grupo estudado, registrando informações obtidas a partir da utilização de todos os sentidos do pesquisador, principalmente sua habilidade de ouvir (ANGROSINO, 2009). No caso da inserção nos grupos de convivência dos adolescentes praticantes do candomblé, esta exigiu dos pesquisadores que estes logo se colocassem no lugar de ouvintes, atentos à recepção dada à própria apresentação da proposta de pesquisa, em um exercício dialógico que, mais do que simplesmente garantir que os sujeitos em foco entendessem o objetivo do trabalho e se interessassem em participar do mesmo, transformasse os primeiros encontros, por si próprios, em etapas ativas da coleta de dados.

Esse diálogo inicial entre pesquisadores e atores sociais nos centros de candomblé trouxe à tona a preocupação desses com sua posição enquanto sujeitos de uma pesquisa cientifica, deixando claro que as preocupações éticas com a entrevista enquanto técnica de experimentação com seres humanos não existem apenas nas discussões dos conselhos de 
saúde brasileiros. De fato, vários integrantes dos centros culturais associados aos terreiros que acolheram os pesquisadores afirmaram já terem sido sujeitos de pesquisas cientificas anteriores que haviam produzido resultados, de sua perspectiva, dúbios. E embora eles não se opusessem a realização de trabalhos acadêmicos em si, criticaram fortemente o fato de que os resultados de tais trabalhos ofereciam pouco ou nenhum retorno significativo aos grupos participantes, não contribuíam para a promoção de mudanças sociais que os beneficiassem e nem mesmo lhes davam qualquer tipo de visibilidade. Nesse sentido, as experiências prévias desses indivíduos se tornaram condições de produção de sentidos, para usar as palavras de Orlandi (2005), significando o próprio ato de interagir com os pesquisadores e ativando a memória discursiva em torno da posição de ser sujeito de uma entrevista. Ou seja, a interação dos integrantes dos centros de candomblé com os pesquisadores agora estava indelevelmente condicionada pelas representações construídas a partir de suas experiências com outros cientistas, uma situação que reforça a premissa de que a informação não pode ser transmitida em uma mão única e que todas as partes envolvidas agem simultaneamente no processo de significação. Assim, a partir do diálogo, novos sentidos puderam ser construídos tanto pelos pesquisadores quanto pelos participantes e, ao longo da pesquisa, a discussão foi retomada em busca de formas de contornar as fragilidades e oferecer uma contrapartida mais adequada aos grupos.

Com a continuidade da interação, os pesquisadores puderam gradativamente se inserir e reconhecer as regras de convivência existentes naquelas comunidades, em um processo que foi deixando claro não apenas as regras de funcionamento das estruturas socioculturais dos grupos observados, mas também, e principalmente, o próprio lugar dos pesquisadores enquanto indivíduos estrangeiros àquelas estruturas. Ao procurar descrever determinados fenômenos culturais observados, os pesquisadores se perceberam, em certos momentos, em choque cultural, tendo seus valores confrontados por aqueles observados. Por outro lado, características próprias dos grupos observados também enfatizaram a posição dos pesquisadores enquanto ouvintes. No candomblé, a transmissão de ensinamentos se dá essencialmente pela oralidade que, como aponta Araujo (2016), é oriunda de tradições africanas desenvolvidas pelas condições de chegada dos africanos no território brasileiro. O valor do conhecimento oral foi testemunhado no desenrolar da inserção dos pesquisadores junto aos grupos de convivência dos terreiros que os acolheram quando os mesmos puderam ouvir - na verdade, foram convidados a ouvir - de forma 
privilegiada, histórias míticas das divindades e trocas de conhecimentos entre seus integrantes, inclusive entre os adolescentes. $\mathrm{E}$, ao presenciar situações pontuais em que os adolescentes ora ensinavam, ora eram ensinados, os pesquisadores se viram obrigados a reelaborar sua percepção acerca dos papeis dos jovens nessas comunidades a partir da compreensão da diversidade de lugares e funções que eles podem ocupar em seus grupos.

Essa ressignificação, por parte dos pesquisadores, acerca do papel dos adolescentes nos grupos de convivência dos terreiros foi apenas enfatizada durante a realização das entrevistas, muitas das quais começaram por iniciativa dos próprios jovens, que procuraram os pesquisadores espontaneamente. Esses sujeitos reconheceram a formação de vínculos com os pesquisadores, enquanto para esses ficava claro que tais vínculos nasciam não apenas graças a sua inserção nos grupos, mas da percepção de que o lugar de escuta que reivindicavam era um lugar ativo, e que toda coleta de dados através de entrevistas e observações era um diálogo nos quais as diferentes partes se influenciavam mutualmente.

\section{Considerações Finais}

Todas essas considerações revolvem em torno do fato de que a própria aplicação dos instrumentos de coleta de dados na pesquisa sobre construções identitárias dos adolescentes das periferias recifenses gerou tantos resultados quanto os próprios dados coletados. Resultados que instigaram os pesquisadores a refletir sobre a própria metodologia empregada não apenas em sua pesquisa, mas nos trabalhos interdisciplinares que recortam e colam técnicas de entrevista e observação participativa, muitas vezes sem considerar as epistemologias por trás delas. E nessa releitura de seu próprio papel enquanto pesquisadores interdisciplinares a percepção de seu lugar enquanto ouvinte desempenhou uma função protagonista, impulsionada tanto pela realização das entrevistas quanto pela escrita dos diários de campo. No caso das entrevistas, sua realização começou guiada por roteiros elaborados a partir de propostas metodológicas da Saúde Coletiva e da História Oral, mas levou a uma reelaboração do próprio foco das perguntas quando o diálogo com os entrevistados, e a posição de ouvinte ativo dos entrevistadores, mostrou o quanto os roteiros preliminares, por mais abertos que fossem, haviam sido elaborados sem a consideração à relação dialógica da entrevista. Os diários de campos, por seu turno, obrigaram os pesquisadores a refletirem, antes de descreverem, acerca dos estímulos 
recebidos nos grupos de convivência, o que lhes levou a ressignificarem sua própria posição nos acontecimentos vivenciados, decompondo e recompondo tanto acontecimentos presenciados quanto vivencias e impressões particulares bem depois de terminada a coleta. Nesse sentido, os pesquisadores se reposicionaram enquanto ouvintes, escutando e compreendendo ativamente, e reconhecendo que estavam participando não de uma coleta de dados laboratorial, mas de conversas nas quais as partes envolvidas se influenciavam mutualmente.

Além disso, longe de qualquer distanciamento e pretensa neutralidade cientifica, 0 emprego da entrevista e da observação participativa junto às comunidades de jovens religiosos deixou transparecer a dubiedade ética existente nas pesquisas qualitativas e sociais ainda realizadas no Brasil, o quanto atores sociais enfocados pela Ciência se não necessariamente são tratados como 'cobaias', são, entretanto, alijados da decisão sobre a utilização dos resultados que ajudaram a construir. Atores sociais despojados de sua autoria discursiva ao serem transformados em objeto de pesquisa por cientistas que escutavam sem ouvir.

Essas reflexões metodológicas só puderam ser feitas a partir de uma imersão em teóricos dedicados aos perigos das técnicas de coleta de dados que usam a fala como matéria. Reflexões trazidas à tona pelo caráter multidisciplinar de uma equipe de pesquisadores oriundos de diferentes disciplinas, uns jogando luz sobre as sombras das técnicas dos outros, e que foram despertados para a importância de sua posição enquanto ouvintes.

\section{Bibliografia Citada}

ABDALA JUNIOR, B. Fronteiras múltiplas, identidades plurais: um ensaio sobre mestiçagem e hibridismo cultural. 1. Ed. São Paulo: Editora SENAC São Paulo, 2002.

ANGROSINO, M. Etnografia e observação participante. Porto Alegre: Artmed, 2009.

ARAUJO, L. A. "As marcas da diáspora negra na oralidade do candomblé baiano." Revista Diálogos, n. 18b, 2016. Disponível em:

<http://www.revistadialogos.com.br/Coneab/Leandro_Alves_Araujo.pdf>. Acesso em: 20 jul. 2019. 
BELEI, R. A. et al. "O uso de entrevista, observação e videogravação em pesquisa qualitativa." Cadernos de Educação, Pelotas, v. 30, p. 187-199, jan./jun. 2008. Disponível em: <https://transcricoes.com.br/wp-content/uploads/2014/11/O-uso-de-entrevistaobserva $\% \mathrm{C}_{3} \% \mathrm{~A} 7 \% \mathrm{C}_{3} \% \mathrm{~A}_{3} 0$-e-videograva $\% \mathrm{C}_{3} \% \mathrm{~A} 7 \% \mathrm{C}_{3} \% \mathrm{~A}_{3}$-em-pesquisa-qualitativa.pdf>. Acesso em: 18 set. 2019.

BONI, V.; QUARESMA, S. J. L. "Aprendendo a entrevistar: como fazer entrevistas em Ciências Sociais." Em tese, v. 2, n. 1, p. 68-80, jan./jul. 2005. Disponível em: <https://periodicos.ufsc.br/index.php/emtese/article/viewFile/18027/16976>. Acesso em: 15 jul. 2019.

BRASIL. Ministério da Educação. Portaria n 1.348, de 14 de dezembro de 2018. Diário oficial da República Federativa do Brasil, Brasília, DF, 17 dez. 2018. Seção 1, p. 33. Disponível em: <https://abmes.org.br/arquivos/legislacoes/Port-MEC-1348-2018-12-14.pdf>. Acesso em: 20 set. 2019.

Ministério da Saúde. Conselho Nacional de Saúde. Resolução n 510, de 7 de abril de 2016. Diário oficial da República Federativa do Brasil, Brasília, DF, 24 maio 2016. Seção 1, p. 44-46. Disponível em:

<http://bvsms.saude.gov.br/bvs/saudelegis/cns/2016/res0510_07_04_2016.html>. Acesso em: 22 set. 2019.

BRITTO JUNIOR, A. F.; FERES JUNIOR, N. "A utilização da técnica da entrevista em trabalhos científicos." Evidência, Araxá, v. 7, n. 7, p. 237-250, 2011. Disponível em: <https://met2entrevista.webnode.pt/_files/200000032-64776656e5/200-752-1-PB.pdf>. Acesso em: 17 jun. 2019.

DINIZ, D. "Ética na pesquisa em ciências humanas: novos desafios." Ciênc. saúde coletiva, Rio de Janeiro, v. 13, n. 2, p. 417-426, abr. 2008. Disponível em:

$<$ http://www.scielo.br/scielo.php?script=sci_arttext\&pid=S1413$81232008000200017 \&$ lng=en\&nrm=iso >. Acesso em: 27 ago. 2019.

DUARTE, R. "Entrevistas em pesquisas qualitativas." Educar, Curitiba: Editora UFPR, n. 24, p. 213-225, 2004. Disponível em: <http://www.scielo.br/pdf/er/n24/n24a11.pdf>. Acesso em: 15 jun. 2019.

FRANCH, M. "Nada para fazer? Um estudo sobre atividades no tempo livre entre jovens de periferia no Recife." Revista Brasileira de Estudos de População, Campinas, v. 19, n.2, p. 117133, jul./dez. 2002. Disponível em:

<https://www.rebep.org.br/revista/article/view/315/pdf_296>. Acesso em: 18 set. 2019.

HALL, S. A identidade cultural na pós-modernidade. 11. ed. Rio de Janeiro: DP\&A, 2006.

JABOATÃO DOS GUARARAPES. Câmara de vereadores. Lei municipal n 1.281, de 10 de maio de 2016. Estabelece a estimular a prática de culto religioso nas escolas do município do Jaboatão dos Guararapes. Diário oficial do município de Jaboatão dos Guararapes, PE, 24 
maio 2016. Disponível em: <https://diariooficial.jaboatao.pe.gov.br/24-de-maio-de-2016ano-xxvi-no89-jaboatao-dos-guararapes/>. Acesso em: 20 set. 2019.

JODELET, D. (Org.). As representações sociais. Rio de Janeiro: EdUERJ, 2001.

MEIHY, J. C. S. B. Manual de História Oral. 4. ed. São Paulo: Edições Loyola, 2002.

MÓNICO, L. S. et al. "A observação participante enquanto metodologia de investigação qualitativa." Investigación Cualitativa en Ciencias Sociales, v. 3, 2017. Disponível em: <https://proceedings.ciaiq.org/index.php/ciaiq2017/article/view/1447/1404>. Acesso em: 13 jul. 2019.

OLIVEIRA, R. C. M. "(Entre)linhas de uma pesquisa: o diário de campo como dispositivo de (in)formação na/da abordagem (auto)biográfica." Revista brasileira de educação de jovens e adultos, v. 2, n. 4, 2014. Disponível em:

<https://www.revistas.uneb.br/index.php/educajovenseadultos/article/view/1059/730>. Acesso em: 20 jul. 2019.

ORLANDI, E. P. Análise do discurso: princípios e procedimentos. 5. ed. Campinas: Pontes, 2005 .

PEREIRA, M. E. M. "Uma aproximação entre Skinner e Bakhtin para o estudo da linguagem." Rev. bras. ter. comport. cogn., São Paulo, v. 9, n. 2, p. 337-347, dez. 2007. Disponivel em: <http://pepsic.bvsalud.org/scielo.php?script=sci_arttext\&pid=S1517$55452007000200014 \&$ lng=pt\&nrm=iso $>$. Acesso em: 28 ago. 2019.

PIRES, V. L. "Dialogismo e alteridade ou a teoria da enunciação em Bakhtin." Organon, UFRGS - Porto Alegre, v. 16, n. 32/33, p. 35-48, 2003. Disponível em:

<https://seer.ufrgs.br/organon/article/view/29782/18403>. Acesso em: 26 set. 2019.

PRYSTHON, Â. F. "Negociações na periferia: mídia e jovens no Recife." In: XXV INTERCOM CONGRESSO BRASILEIRO DE CIÊNCIA DA COMUNICAÇÃO, 2002, Salvador. Anais...

Salvador: Intercom, 2002. p. 1-13. Disponível em:

<http://www.portcom.intercom.org.br/pdfs/104525624850818804175930761218920877972. pdf>. Acesso em: 20 set. 2019.

REVISÃO ÉTICA NA PESOUISA EM CIÊNCIAS HUMANAS E SOCIAIS. Educ. Soc., Campinas, v. 36, n. 133, p. 857-863, dez. 2015. Disponível em:

$<$ http://www.scielo.br/scielo.php?script=sci_arttext\&pid=S0101-

$73302015000400857 \&$ lng=en\&nrm=iso $>$. Acesso em: 27 ago. 2019.

SILVA, M. A. "A técnica da observação nas ciências humanas." Educativa, Goiânia, v. 16, n. 2, p. 413-423, jul./dez. 2013. Disponível em:

<http://seer.pucgoias.edu.br/index.php/educativa/article/view/3101/1889>. Acesso em: 12 jul. 2019. 
SILVEIRA, E. S. "História Oral e memória: pensando um perfil de historiador etnográfico." Métis: história \& cultura, v. 6, n. 12, p. 35-44, jul./dez. 2007. Disponível em: <http://www.ucs.br/etc/revistas/index.php/metis/article/view/835/592>. Acesso em: 15 set. 2019.

\footnotetext{
'Professora Associada da Universidade de Pernambuco (UPE), Doutora em História pela UFPE, Pós-Doutora em História pela Universidade de Salamanca (Espanha), Livre-docente pela Universidade de Pernambuco (UPE).

E-mail: kalinavan@uol.com.br

ii Mestre em Hebiatria pela Universidade de Pernambuco (UPE); Enfermeira graduada pela Universidade Federal de Pernambuco (UFPE).

E-mail: simonellyvilela@hotmail.com

iii Mestre em Hebiatria pela Universidade de Pernambuco (UPE); Psicólogo clínico pela Universidade Federal de Pernambuco (UFPE).

E-mail: dougbatista.oliver@gmail.com

${ }^{\text {iv }}$ Professor Adjunto da Universidade de Pernambuco (UPE), Doutor em Antropologia pela UFPE.

E-mail andervicensil@yahoo.com.br
} 